\title{
Bisacodyl and Sodium Picosulfate Improve Bowel Function and Quality of Life in Patients with Chronic Constipation-Analysis of Pooled Data from Two Randomized Controlled Trials
}

\author{
Stefan Müller-Lissner1, Erika Richter², Marion Eberlin'², Harald Weigmann², \\ Tobias Mück², Michael A. Kamm ${ }^{3}$ \\ ${ }^{1}$ Department of Internal Medicine, Park-Klinik Weissensee, Berlin, Germany \\ ${ }^{2}$ Sanofi-Aventis GmbH, Frankfurt-Hoechst, Germany \\ ${ }^{3}$ St Vincent's Hospital, University of Melbourne, Melbourne, Australia \\ Email: stefan@mueller-lissner.de
}

How to cite this paper: Müller-Lissner, S., Richter, E., Eberlin, M., Weigmann, H., Mück, T. and Kamm, M.A. (2017) Bisacodyl and Sodium Picosulfate Improve Bowel Function and Quality of Life in Patients with Chronic Constipation-Analysis of Pooled Data from Two Randomized Controlled Trials. Open Journal of Gastroenterology, 7, 32-43.

http://dx.doi.org/10.4236/ojgas.2017.71005

Received: September 20, 2016

Accepted: January 20, 2017

Published: January 23, 2017

Copyright $\odot 2017$ by authors and Scientific Research Publishing Inc. This work is licensed under the Creative Commons Attribution International License (CC BY 4.0).

http://creativecommons.org/licenses/by/4.0/ (c) (i) Open Access

\begin{abstract}
Background: Quality of life (QoL) is impaired in chronic constipation. Among nonprescription laxatives QoL data out of randomized controlled trials are available only for bisacodyl and sodium picosulfate (SPS). Methods: In two randomized, double-blind, placebo-controlled, parallel-group trials, the efficacy and safety of treatment with either bisacodyl or SPS, respectively, were assessed. After a 2-week baseline period patients with functional constipation were randomized to a 4-week treatment with either bisacodyl ( 2 tablets $=10 \mathrm{mg}$ ), SPS (18 drops = $10 \mathrm{mg}$ ), or matching placebo in a ratio of active drug to placebo of 2:1. Dose reduction as well as resuming the original dose was permitted. Patients who did not experience a bowel movement for more than $72 \mathrm{~h}$ were allowed to use a bisacodyl suppository. The primary endpoint was the mean number of Complete Spontaneous Bowel Movements (CSBMs) per week during the trial. QoL was assessed using the Patient Assessment of Constipation (PAC)-QoL questionnaire. Results: Active treatment led to a greater improvement of PAC-QoL scores for every domain. Active treatment was also superior to placebo for all individual questions of the questionnaire. Of note, SPS or bisacodyl not only improved satisfaction with stool patterns ("quite a bit/extremely satisfied" in $12.8 \%$ of patients on placebo and $50.3 \%$ on active treatment) but bloating was also considerably ameliorated ("not at all feeling bloated" in $24.5 \%$ on placebo and $41.4 \%$ on active treatment). Conclusion: Bisacodyl and SPS not only improve stool variables but also quality of life in patients with chronic functional constipation. (EudraCT Nos. 2007-001991-34 and 2007-002087-10).
\end{abstract}




\section{Keywords}

Constipation, Laxative, Bisacodyl, Sodium Picosulfate, Quality of Life

\section{Introduction}

Constipation is a common complaint affecting all ages being more common in women than in men [1]. In the majority of cases, no cause can be identified. Lifestyle changes such as exercise, food, and fluid intake have neither been proven as risk factors nor as effective treatment modalities [2]. However, chronic constipation is only reluctantly accepted as a relevant health problem. There is convincing scientific as well as medical evidence that constipated patients are bothered by a variety of harassing symptoms often associated with high psychological strain, resulting in lower quality of life as compared to individuals without constipation [3]. The impact of chronic constipation on quality of life is described to be comparable to other chronic conditions. For example, the physical component score of the SF-36 questionnaire was 48.1 in chronic constipation, 49.5 in allergies, 47.7 in dermatitis and 47.4 in ulcerative colitis [4].

Bisacodyl (BIS) has been developed in the 1950s, and its chemical congener sodium picosulfate (SPS) in the late 1960s. Both these diphenyl methane derivatives are prodrugs converted in the gut into the same active metabolite, bis- $(p$ -hydroxyphenyl)-pyridyl-2-methane (BHPM). BHPM has a dual action, namely an antiabsorptive-secretory effect and also a direct prokinetic effect [5] [6]. Only minor amounts are systemically absorbed but are not considered to contribute to the laxative action since the laxative effect of bisacodyl or SPS does not correlate with the plasma level of BHPM. The clinical efficacy of bisacodyl and SPS is generally not questioned and was further confirmed by recently conducted stateof-the-art trials [7] [8]. In these randomized, double-blind, placebo-controlled, parallel-group clinical trials, measures of quality of life (QoL) were obtained by the PAC-QoL questionnaire in addition to the bowel movement frequency, which is commonly used as objective outcome parameter in clinical trials to assess the efficacy of laxative treatment. However, besides this objective variable, patients' reported symptoms and their improvement offer another valuable tool to judge treatment benefit. The objective of this pooled analysis is to show the impact of SPS/BIS on health-related quality of life. Since the PAC-QoL data from neither of these trials have been published in detail, the data from the two studies were pooled, and the results from the pooled analysis were presented in the present paper.

\section{Methods}

The methodology of the trials has been described in detail previously [7] [8]. In brief, a randomized, double-blind, placebo-controlled, parallel-group design to assess the efficacy and safety of treatment with either bisacodyl tablets or SPS drops, respectively, was followed. Male and female patients aged $\geq 18$ years suf- 
fering from functional constipation according to the Rome III diagnostic criteria [1] were eligible for the trial if able and willing to complete a daily eDiary, able and willing to use the rescue medication, and having signed written informed consent. At the end of a 2-week baseline period to record bowel symptoms they were randomized to a 4 -week treatment if functional constipation was confirmed by diary data according to the following definition: less than three complete spontaneous bowel movements (CSBMs) per week on average, together with at least one of the following symptoms occurring at least $25 \%$ of the time: straining, incomplete evacuation, and/or lumpy or hard stools (i.e. type 1 or type 2 stools according to the seven-point Bristol Stool Form Scale [9]). The following exclusion criteria were applied at screening: eating disorders such as anorexia nervosa and bulimia as a cause of excessive use of laxatives; constipation caused by organic disease, metabolic, or neurological disorders; severe psychiatric disorders or any other significant disease or intercurrent illness that, in the investigators' opinion, would have interfered with participation in the trial; restricted mobility (e.g., wheelchair bound or bedridden) that, in the investigators ' opinion, would have interfered with participation in the trial; intestinal obstruction; acute surgical abdominal conditions; anal fissure; ulcerative colitis; clinically significant abnormal electrolyte values; concomitant opioid medication; constipation caused by medication in the investigators' opinion; premenopausal women who were breast-feeding or pregnant or who were of childbearing potential and were not using an acceptable method of birth control throughout the study; participation in another trial with an investigational product within 1 month before enrollment into this study; drug or alcohol abuse; and concomitant use of antibiotics.

Patients received $10 \mathrm{mg}$ of either bisacodyl tablets, SPS drops, or matching placebo. In both trials the ratio of active drug to placebo was 2:1. Study medication was administered once daily in the evening. Halving the dose was permitted according to the patient's need. The patient was also allowed to resume the original dose. Patients who did not experience a bowel movement for more than $72 \mathrm{~h}$ were allowed to use a bisacodyl suppository as rescue medication.

The primary endpoint was the mean number of CSBMs/week during the 4-week treatment phase of the trial. A spontaneous bowel movement (SBM) was defined as a stool not induced by rescue medication and a CSBM was defined as an SBM with a sensation of complete evacuation.

Quality of life (QoL) was assessed using the Patient Assessment of Constipation (PAC)-QoL questionnaire. The PAC-QoL is a 28 -item self-administered QoL instrument designed to evaluate a patient's assessment of constipation over time. It generates five scores, a total scale score, and four specific subscale scores (worries and concerns (11 items); physical discomfort (4 items); psychosocial discomfort (8 items); satisfaction (5 items)). For the wording of the single PAC-QoL scores, see Table 4. Minimal and maximal values for each question are 0 and 4, respectively. The study protocols were registered under the EudraCT Nos. 2007-001991-34 and 2007-002087-10. They were approved by the local ethical committees. 


\section{Statistics}

The sample size calculations in each trial were based on the primary endpoint. A sample size of 200 patients in the study groups receiving the active drug and 100 patients in the placebo groups would have a $90 \%$ power to detect a difference of 1 in the mean number of CSBMs per week with a 0.05 two-sided significance level. Anticipating a dropout rate of $20 \%$, approximately 240 patients in the active-drug group and 120 patients in the placebo group were to be entered (randomized) into each of the trials.

The results presented in the following are based on the full analysis set (FAS = all randomized patients who took at least one dose of trial medication and who provided any data for the primary efficacy endpoint during the randomized treatment phase, including the combined data of the two studies).

The mean number of CSBMs/week over 4 weeks as well as the improvement in the PAC-QoL subscale scores (worries and concerns, physical discomfort, psychosocial discomfort, satisfaction and overall score) from baseline were analyzed using analysis of covariance (ANCOVA) including trial and treatment (SPS/BIS) as fixed effects and the respective baseline value as continuous covariate. Treatment differences were estimated by reference to the adjusted least square means and the corresponding $95 \%$ confidence intervals.

For the change from baseline in each of the 28 single PAC-QoL scores, ordinal logistic regression models adjusting for trial and the baseline PAC-QoL score were used. Likelihood-ratio tests were used to test for treatment differences. Adjusted odds ratios together with $95 \%$ confidence intervals were used to quantify the treatment effect, comparing SPS/BIS and placebo.

\section{Results}

In the two trials 1204 patients were enrolled (screened), 468 patients in the SPS trial and 736 in the bisacodyl trial. The pooled full analysis set (FAS) comprised 718 patients (SPS/BIS: 468, placebo: 250). Demographic and baseline data for the pooled FAS are given in Table 1. During the 4 weeks treatment period, less than $5 \%$ of the patients discontinued the studies prematurely. Slightly higher dropout rates in the active drug groups were due to the increased occurrence of diarrhea, probably due to a fixed dosage regimen at start of therapy which could be adapted in the course of the study.

The number of CSBMs/week increased from a baseline of 1 and 1.1, respectively, to a mean of 4.4 over 4 weeks with active treatment SPS/BIS and to 1.8 with placebo (see Table 2).

The results for the improvement in the PAC-QoL subscale scores from baseline are shown in Table 3 and Figure 1. Active treatment led to a greater improvement of PAC-QoL scores for every domain: Mean improvements (adjusted for trial and baseline value) from baseline to week 4 in the active treatment group vs. placebo were: 0.94 vs. 0.28 points (overall score), 0.68 vs. 0.20 points (worries and concerns), 1.09 vs. 0.35 points (physical discomfort), 0.41 vs. 0.19 (psychosocial discomfort), and 1.57 vs. 0.35 (satisfaction). 
Table 1. Demographic and baseline data for the pooled full analysis set (pooled FAS).

\begin{tabular}{ccc}
\hline & Placebo & SPS/BIS \\
\hline Number of patients & 250 & 468 \\
Gender [N (\%)] & & \\
Male & $44(17.6)$ & $126(26.9)$ \\
Female & $206(82.4)$ & $342(73.1)$ \\
Age [years] & & \\
Mean (SD) & $53.1(15.91)$ & $52.9(16.75)$ \\
Baseline number of CSBMs \\
$\quad$ Mean (SD) & $1.1(1.27)$ & $1.0(1.30)$ \\
Baseline PAC-QoL-overall score & & $1.99(0.700)$ \\
Mean (SD) & $1.95(0.650)$ & $1.66(0.898)$ \\
Baseline PAC-QoL-worries and concerns & & \\
Mean (SD) & $1.59(0.815)$ & \\
Baseline PAC-QoL-physical discomfort & & $1.15(0.895)$ \\
Mean (SD) & $2.18(0.830)$ & $2.90(0.837)$ \\
Baseline PAC-QoL-psychosocial discomfort & &
\end{tabular}

Table 2. Adjusted mean (SE) for the mean number of CSBMs/week over the 4 weeks treatment period (pooled FAS).

\begin{tabular}{ccc}
\hline & Placebo & SPS/BIS \\
\hline $\begin{array}{c}\text { Number of patients } \\
\text { Baseline number of CSBMs/week } \\
\text { Mean (SE) }\end{array}$ & 250 & 468 \\
Mean of CSBMs/week over 4 weeks & $1.1(0.08)$ & $1.0(0.06)$ \\
Adjusted ${ }^{*}$ mean (SE) & & \\
Comparison vs. Placebo & $1.8(0.18)$ & $4.4(0.13)$ \\
Adjusted ${ }^{*}$ mean (SE) & & \\
$95 \%$ Confidence Interval \\
$p$-value & & $2.5(0.22)$ \\
& & $<0.0001$ \\
\hline
\end{tabular}

${ }^{\star}$ Adjusted for trial and baseline value.

Table 3. Adjusted mean (SE) improvement in the PAC-QoL scale scores from baseline (pooled FAS).

\begin{tabular}{cccccc}
\hline & \multicolumn{3}{c}{ Adjusted $^{*}$ mean (SE) } & \multicolumn{3}{c}{ Comparison vs. Placebo } \\
\cline { 2 - 6 } & Placebo & SPS/BIS & $\begin{array}{c}\text { Adjusted }{ }^{*} \text { mean } \\
(\text { SE) }\end{array}$ & $\begin{array}{c}95 \% \text { confidence } \\
\text { interval }\end{array}$ & $p$-value \\
\hline $\begin{array}{c}\text { Worries and } \\
\text { concerns }\end{array}$ & $0.20(0.04)$ & $0.68(0.03)$ & $0.48(0.05)$ & $(0.37,059)$ & $<0.0001$ \\
$\begin{array}{c}\text { Physical discomfort } \\
\text { Psychosocial } \\
\text { discomfort }\end{array}$ & $0.35(0.05)$ & $1.09(0.04)$ & $0.73(0.07)$ & $(0.61,0.86)$ & $<0.0001$ \\
$\begin{array}{c}\text { Satisfaction } \\
\text { Overall score }\end{array}$ & $0.19(0.04)$ & $0.41(0.03)$ & $0.22(0.05)$ & $(0.11,0.32)$ & $<0.0001$ \\
\hline
\end{tabular}

*Adjusted for trial and baseline value. 


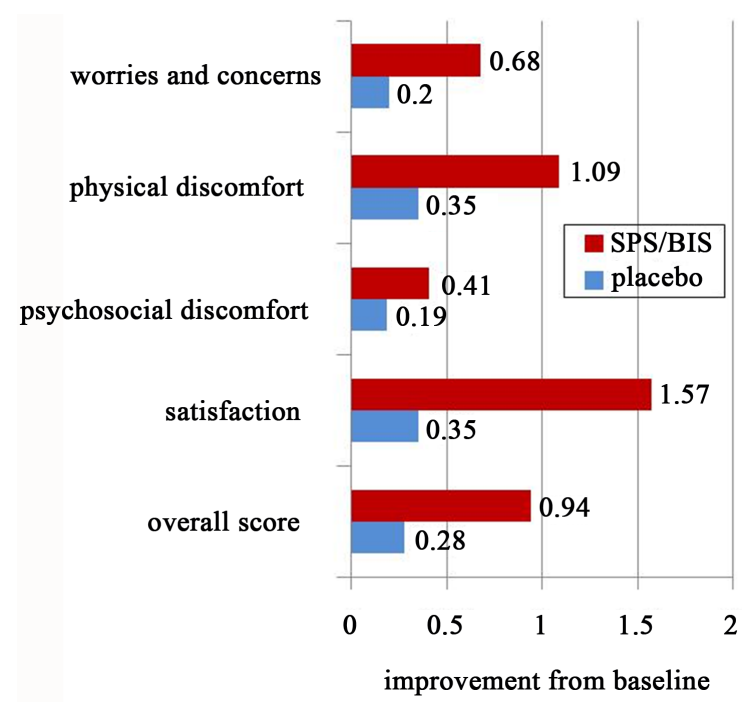

Figure 1. Adjusted means (SE) for the improvement in the subscale scores of the PACQoL questionnaire from baseline for SPS/BIS and placebo, respectively (pooled FAS).

A greater percentage of patients in the BIS/SPS group then in the placebo group had an improvement of $\geq 1$ point $(p<0.0001)$ for PAC-QOL and the subscale scores satisfaction and physical discomfort.

With BIS/SPS $47.0 \%, 64.3 \%$ and $54.5 \%$ of patients achieved a clinical relevant improvement in the PAC-QOL overall score, the satisfaction score and the physical discomfort score, compared to $14.5 \%, 26.1 \%$ and $21.7 \%$ with placebo, respectively.

Since patients complaining of constipation suffer especially from dissatisfaction with their bowel function, some respective symptoms have been selected for graphical presentation, and their corresponding pre- and post-treatment assessments are shown in Figure 2. Odds ratios (ORs) for the improvement in single PAC-QoL scores concerning satisfaction with bowel function (questions 24-27) were highly in favor of SPS/BIS when compared to placebo: 7.6, 7.3, 6.2 and 6.7 , respectively. ORs together with $95 \%$ confidence intervals are displayed in Table 4. As can be seen, improvement covered a large range of symptoms comprising not only the area of bowel movements, but also of appetite, eating, and social interaction. Figure 2 shows this in more detail for selected Items. There was a clear positive shift from pre treatment to post treatment in the group on active treatment but not in the placebo group.

\section{Discussion}

Although chronic constipation-in contrast to other functional gastrointestinal disorders-is associated with a slightly reduced survival (hazard ratio 1.19) [10] presumably particularly due to cardiovascular events [11] the main negative impact is the one on quality of life (QoL) [3] [12]. The primary endpoint in therapeutic trials in chronic constipation is usually a stool variable such as a minimal number or minimal increase, respectively, of complete spontaneous bowel movements [13]. This was also the case in our two trials with bisacodyl and SPS. 
Table 4. Odds ratios and 95\% confidence intervals for the improvement in single PAC-QoL scores with regard to patients' physical discomfort and satisfaction with bowel function (pooled FAS).

\begin{tabular}{|c|c|c|c|}
\hline \multirow{2}{*}{ Single item PAC-QoL } & \multicolumn{3}{|c|}{ Comparison versus Placebo } \\
\hline & Odds ratio & ( $95 \%$ confidence interval) & $p$-value \\
\hline 1: Have you felt bloated to the point of bursting? & 3.412 & $(2.517,4.624)$ & $<0.0001$ \\
\hline 2: Have you felt heavy because of your constipation? & 5.931 & $(4.312,8.160)$ & $<0.0001$ \\
\hline 3: Have you felt any physical discomfort? & 2.576 & $(1.910,3.474)$ & $<0.0001$ \\
\hline 4: Have you felt the need to open your bowel but not been able to? & 5.157 & $(3.776,7.043)$ & $<0.0001$ \\
\hline 5: Have you been embarrassed to be with other people? & 1.563 & $(1.134,2.156)$ & 0.0064 \\
\hline 6: Have you been eating less and less because of not being able to have bowel movements? & 3.023 & $(2.200,4.155)$ & $<0.0001$ \\
\hline 7: Have you had to be careful about what you eat? & 2.545 & $(1.874,3.456)$ & $<0.0001$ \\
\hline 8: Have you had a decreased appetite? & 1.875 & $(1.361,2.583)$ & 0.0001 \\
\hline $\begin{array}{l}\text { 9: Have you been worried about not being able to choose what you eat } \\
\text { (for example, at friend's)? }\end{array}$ & 2.365 & $(1.689,3.313)$ & $<0.0001$ \\
\hline $\begin{array}{l}\text { 10: Have you been embarrassed about staying in the toilet for } \\
\text { so long when you were away from home? }\end{array}$ & 1.434 & $(1.067,1.928)$ & 0.0170 \\
\hline $\begin{array}{l}\text { 11: Have you been embarrassed about having to go to the toilet } \\
\text { so often when you were away from home? }\end{array}$ & 0.837 & $(0.622,1.127)$ & 0.2407 \\
\hline $\begin{array}{l}\text { 12: Have you been worried about having to change your daily routine } \\
\text { (for example, travelling, being away from home)? }\end{array}$ & 0.894 & $(0.665,1.203)$ & 0.4599 \\
\hline 13: Have you felt irritable because of your condition? & 3.004 & $(2.207,4.088)$ & $<.0001$ \\
\hline 14: Have you been upset by your condition? & 3.413 & $(2.501,4.656)$ & $<0.0001$ \\
\hline 15: Have you felt obsessed by your condition? & 2.148 & $(1.576,2.927)$ & $<0.0001$ \\
\hline 16: Have you felt stressed by your condition? & 2.405 & $(1.775,3.257)$ & $<0.0001$ \\
\hline 17: Have you been less self-confident because of your condition? & 1.671 & $(1.223,2.282)$ & 0.0012 \\
\hline 18: Have you felt in control of your situation? & 1.650 & $(1.236,2.203$ & 0.0007 \\
\hline $\begin{array}{l}\text { 19: Have you been worried about not knowing when you are } \\
\text { going to be able to open your bowels? }\end{array}$ & 1.783 & $(1.328,2.394)$ & 0.0001 \\
\hline 20: Have you been worried about not being able to open your bowels when you needed to? & 3.615 & $(2.663,4.908)$ & $<0.0001$ \\
\hline 21: Have you been more and more bothered by not being able to open your bowels? & 3.845 & $(2.819,5.244)$ & $<0.0001$ \\
\hline 22: Have you been afraid that your condition will get worse? & 3.314 & $(2.422,4.535)$ & $<0.0001$ \\
\hline 23: Have you felt that your body was not working properly? & 3.214 & $(2.377,4.344)$ & $<0.0001$ \\
\hline 24: Have you had fewer bowel movements than you would like? & 7.566 & $(5.468,10.470)$ & $<0.0001$ \\
\hline 25: Have you been satisfied with how often you open your bowels? & 7.336 & $(5.319,10.118)$ & $<0.0001$ \\
\hline 26: Have you been satisfied with the regularity with which you open your bowels? & 6.160 & $(4.508,8.418)$ & $<0.0001$ \\
\hline 27: Have you been satisfied with your bowel function? & 6.711 & $(4.894,9.201)$ & $<0.0001$ \\
\hline 28: Have you been satisfied with your treatment? & 4.162 & $(4.508,8.418)$ & $<0.0001$ \\
\hline
\end{tabular}




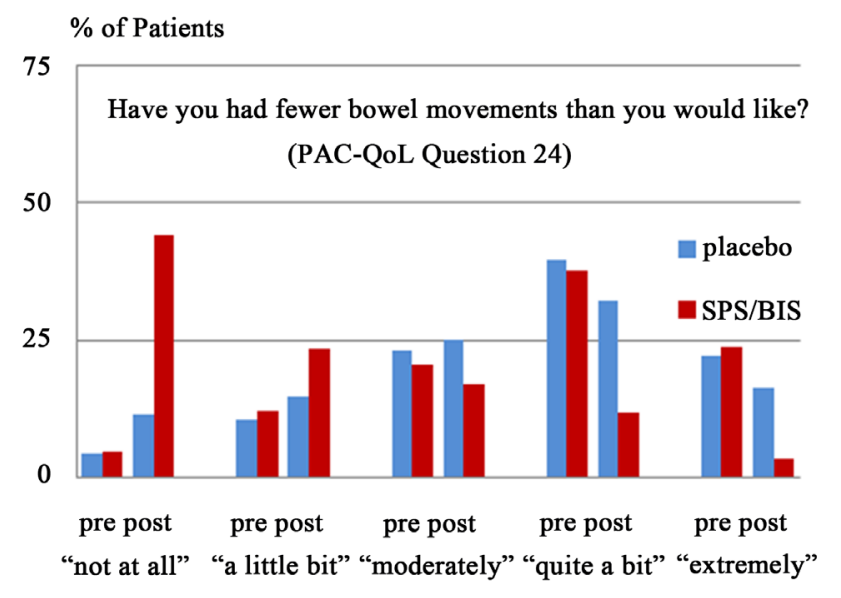

(a)

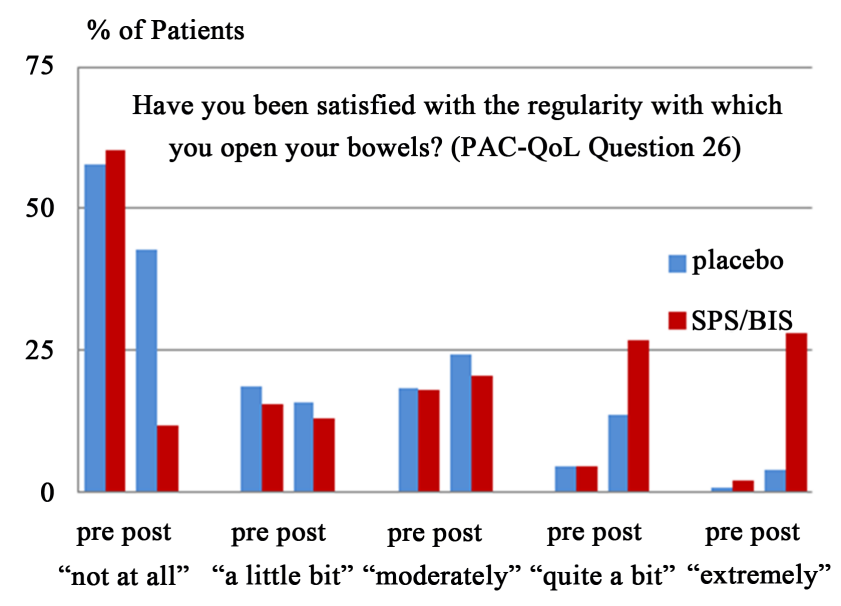

(c)

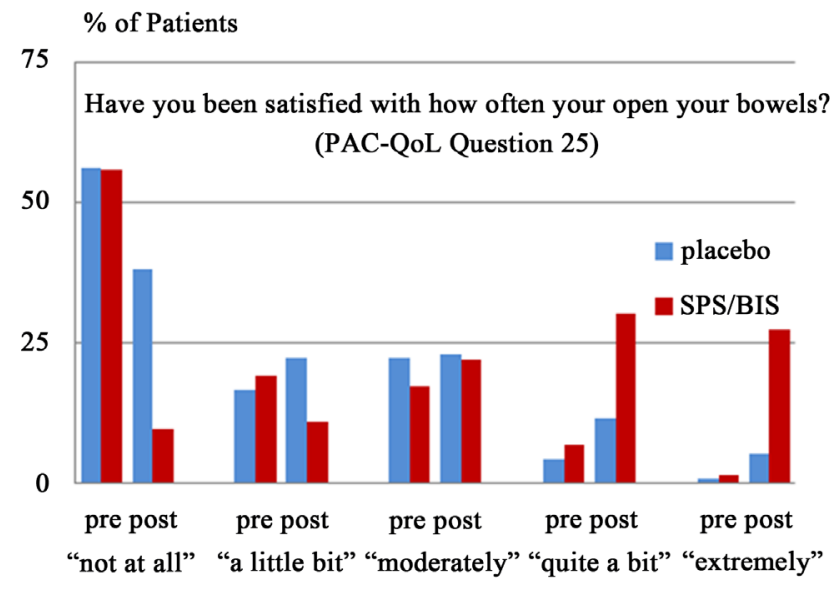

(b)

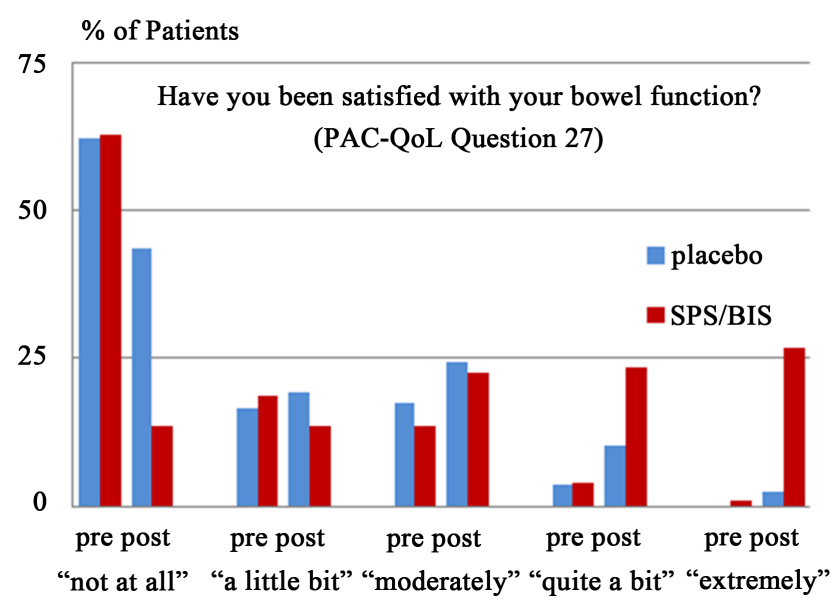

(d)

Figure 2. (a)-(d) Proportion of patients for single scores concerning satisfaction with bowel function (questions 24 - 27) from the PAC-QoL questionnaire at the beginning and at the end of treatment for SPS/BIS and placebo, respectively-pooled FAS. Questions showing Odds ratios $>6$ were chosen for graphical presentation.

Since perceived quality of life is probably more relevant as any stool variable we present the respective data on PAC-QoL from a combined analysis of our sibling trials. Pooled analysis of the data from these trials is meaningful since the active principle of bisacodyl and SPS is the same [14] and the trials followed an identical protocol. A similar combined analysis has been done for prucalopride showing that the PAC-QoL questionnaire is a useful measurement tool to assess the potential therapeutic value of laxatives in clinical trials from a patient perspective [15].

As already published in one of our individual papers the improvement in symptoms of constipation was reflected in all of the dimensions of the global SF-36v2 assessment [8]. Generic questionnaires as the SF-36v2 focus on broader aspects of QoL, and are intended for use in general populations or across a wider range of disorders. Specific disease and treatment-related effects are generally better detected by disease-specific instruments. The latter are developed to assess dimensions of health that are likely to be affected by the intervention in the re- 
spective study. Thus, the disease-specific PAC-QoL seems to be even more suitable for detecting treatment-induced changes in patients with constipation than the generic questionnaire SF-36. The improvement in disease-specific, constipation-related QoL (PAC-QoL) scores was in favor of SPS/BIS, reflecting an improvement in patients' everyday functioning and well-being. The descriptive $p$ values of the Odds ratios were all below 0.05 except for questions 11 and 12 . These two questions refer to diarrheal states and should not be positively affected by laxatives such as SPS/BIS. Results from these two clinical trials [7] [8] are the first published data demonstrating the impact of these non-prescription laxatives on QoL in placebo-controlled, randomized trials though observational data did already suggest such an effect. Interviews in 86 women with chronic constipation by two self-administered questionnaires, the Psychological General Well-Being Index (PGWB) and the Gastrointestinal Symptom Rating Scale (GSRS), revealed that psychological well-being according to the PGWB was better for the subjects using SPS regularly than for those using other laxatives [16]. In general, treating chronic constipation with a laxative regimen is beneficial for QoL [17]. Whether this applies also to pelvic floor dyssynergia or whether this condition is more amenable to biofeedback treatment is, however, questionable because of the lack of high-quality evidence as shown in a recent meta-analysis [18].

Both bisacodyl and its chemically congener sodium picosulfate have an antiabsorptive-secretory effect [5] [19] and are very potent prokinetics in the colon [6] [20] [21]. Since improvement in PAC-SYM (Patient Assessment of Constipation Symptoms) scores correlated well with an improvement in PAC-QoL overall score and the satisfaction subscale score [22] it is not astonishing that these potent laxatives improve QoL in afflicted patients.

A particular problem poses opioid induced constipation since QoL can be reduced due to pain, the underlying disease, as well as the side effects of opioids, particularly constipation [23] [24]. Though with long-term use many side effects associated with opioid therapy subside because of tolerance, constipation does apparently not and can significantly affect QoL [23]. In patients taking opioids, constipation may be even more distressing for the patient than the pain itself [25]. Respondents in the 2012 US National Health and Wellness Survey reporting current use of opioids for more than 30 days and experiencing constipation were categorized as making modifications to opioid therapy due to constipation or not. Modifiers reported poorer health related QoL, worse constipation, more pain-related resource use, and lower adherence than non-modifiers [26]. For the treatment of opioid induced constipation indirect evidence favors bisacodyl, SPS, and macrogol as first choice laxatives [27]. In addition, bisacodyl is used as the rescue laxative in most of the therapeutic trials for Opioid Induced Constipation (OIC), and the amount taken is considered a sensitive variable for the efficacy of the drug under investigation.

A limitation of this pooled analysis is the lack of direct head-to-head comparisons with other laxatives such as macrogol, prucalopride, linaclotide, and lubi- 
prostone. Unfortunately, this kind of studies is not easy to conduct.

\section{Conclusion}

Among self-medicated laxatives, bisacodyl and sodium picosulfate are the only drugs which have been shown to considerably improve quality of life in patients with chronic constipation based on randomized clinical trials when treated over 4 weeks.

\section{Authorship Statement}

Guarantor of the article: Stefan Müller-Lissner.

Specific author contributions:

Conducting the trials: Michael Kamm, Stefan Müller-Lissner.

Statistical analysis: Erika Richter.

Manuscript writing and review: all authors.

\section{Conflict of Interest}

Stefan Müller-Lissner was financially supported for writing the manuscript; Michael Kamm served as advisor for Boehringer Ingelheim. Erika Richter, Marion Eberlin, Harald Weigmann, and Tobias Mück are former employees of Boehringer Ingelheim. Since 1 January 2017 they are employees of Sanofi-Aventis. Both trials were sponsored by Boehringer Ingelheim

\section{References}

[1] Longstreth, G.F., Thompson, W.G., Chey, W.D., Houghton, L.A., Merian, F. and Spiller, R.C. (2006) Functional Bowel Disorders. Gastroenterology, 130, 1480-1491. https://doi.org/10.1053/j.gastro.2005.11.061

[2] Mueller-Lissner, S., Kamm, M.A., Scarpignato, C. and Wald, A. (2005) Myths and Misconceptions about Chronic Constipation. The American Journal of Gastroenterology, 100, 232-242. https://doi.org/10.1111/j.1572-0241.2005.40885.x

[3] Wald, A., Scarpignato, C., Kamm, M.A., Mueller-Lissner, S., Helfrich, I., Schuijt, C., Bubeck, J., Limoni, C. and Petrini, O. (2007) The Burden of Constipation on Quality of Life: Results of a Multinational Survey. Alimentary Pharmacology \& Therapeutics, 26, 227-236. https://doi.org/10.1111/j.1365-2036.2007.03376.x

[4] Belsey, J., Greenfield, S., Candy, D. and Geraint, M. (2010) Systematic Review: Impact of Constipation on Quality of Life in Adults and Children. Alimentary Pharmacology \& Therapeutics, 31, 938-949. https://doi.org/10.1111/j.1365-2036.2010.04273.x

[5] Ewe, K. (1987) Effect of Bisacodyl on Intestinal Electrolyte and Water Net Transport and Transit. Perfusion Studies in Men. Digestion, 37, 247-253. https://doi.org/10.1159/000199508

[6] Hervé, S., Savoye, G., Behbahani, A., Leroi, A.M., Denis, P. and Ducrotté, P. (2004) Results of 24-h Manometric Recording of Colonic Motor Activity with Endoluminal Instillation of Bisacodyl in Patients with Severe Chronic Slow Transit Constipation. Neurogastroenterology \& Motility, 6, 397-402. https://doi.org/10.1111/j.1365-2982.2004.00535.x

[7] Kamm, M.A., Wald, A., Richter, E., Swallow, R. and Gessner, U. (2011) Oral Bisa- 
codyl Is Effective and Well-Tolerated in Patients with Chronic Constipation. Clinical Gastroenterology and Hepatology, 7, 577-583.

https://doi.org/10.1016/j.cgh.2011.03.026

[8] Mueller-Lissner, S., Kamm, M.A., Wald, A., Hinkel, U., Koehler, U., Richter, E. and Bubeck, J. (2010) Multicenter, 4-Week, Double-Blind, Randomized, Placebo-Controlled Trial of Sodium Picosulfate in Patients with Chronic Constipation. The American Journal of Gastroenterology, 105, 897-903. https://doi.org/10.1038/ajg.2010.41

[9] Lewis, S.J. and Heaton, K.W. (1997) Stool Form Scale as a Useful Guide to Intestinal Transit Time. Scandinavian Journal of Gastroenterology, 32, 920-924. https://doi.org/10.3109/00365529709011203

[10] Chang, J.Y., Locke III, G.R., McNally, M.A., Halder, S.L., Schleck, C.D., Zinsmeister, A.R. and Talley, N.J. (2010) Impact of Functional Gastrointestinal Disorders on Survival in the Community. The American Journal of Gastroenterology, 105, 822832. https://doi.org/10.1038/ajg.2010.40

[11] Honkura, K., Tomata, Y., Sugiyama, K., Kaiho, Y., Watanabe, T., Zhang, S., Sugawara, Y. and Tsuji, I. (2016) Defecation Frequency and Cardiovascular Disease Mortality in Japan: The Ohsaki Cohort Study. Atherosclerosis, 246, 251-256. https://doi.org/10.1016/j.atherosclerosis.2016.01.007

[12] Johanson, J.F. and Kralstein, J. (2007) Chronic Constipation: A Survey of the Patient Perspective. Alimentary Pharmacology \& Therapeutics, 25, 599-608. https://doi.org/10.1111/j.1365-2036.2006.03238.x

[13] Ford, A.C. and Suares, N.C. (2011) Effect of Laxatives and Pharmacological Therapies in Chronic Idiopathic Constipation: Systematic Review and Meta-Analysis. Gut, 60, 209-218. https://doi.org/10.1136/gut.2010.227132

[14] Jauch, R., Hankwitz, K., Beschke, K. and Pelzer, H. (1975) Bis-(P-Hydroxy-phenyl)Pyridyl-2-Methane: The Common Laxative Principle of Bisacodyl and Sodium Picosulfate. Arzneimittelforschung, 25, 1796-1800.

[15] Dubois, D., Gilet, H., Viala-Danten, M. and Tack, J. (2010) Psychometric Performance and Clinical Meaningfulness of the Patient Assessment of Constipation-Quality of Life Questionnaire in Prucalopride (RESOLOR ${ }^{\otimes}$ ) Trials for Chronic Constipation. Neurogastroenterology \& Motility, 22, e54-e63. https://doi.org/10.1111/j.1365-2982.2009.01408.x

[16] Bengtsson, M. and Ohlsson, B. (2005) Psychological Well-Being and Symptoms in Women with Chronic Constipation Treated with Sodium Picosulphate. Gastroenterology Nursing, 28, 3-12. https://doi.org/10.1097/00001610-200501000-00002

[17] Ostaszkiewicz, J., Hornby, L., Millar, L. and Ockerby, C. (2010) The Effects of Conservative Treatment for Constipation on Symptom Severity and Quality of Life in Community-Dwelling Adults. Journal of Wound Ostomy \& Continence Nursing, 37, 193-198. https://doi.org/10.1097/WON.0b013e3181cf7206

[18] Koh, C.E., Young, C.J., Young, J.M. and Solomon, M.J. (2008) Systematic Review of Randomized Controlled Trials of the Effectiveness of Biofeedback for Pelvic Floor Dysfunction. British Journal of Surgery, 95, 1079-1087. https://doi.org/10.1002/bjs.6303

[19] Binder, H.J. and Donowitz, M. (1975) A New Look at Laxative Action. Gastroenterology, 69, 1001-1005.

[20] Bassotti, G., Chiarioni, G., Germani, U., Battaglia, E., Vantini, I. and Morelli, A. (1999) Endoluminal Instillation of Bisacodyl in Patients with Severe (Slow Transit Type) Constipation Is Useful to Test Residual Colonic Propulsive Activity. Diges- 
tion, 60, 69-73. https://doi.org/10.1159/000007591

[21] Manabe, N., Cremonini, F., Camilleri, M., Sandborn, W.J. and Burton, D.D. (2009) Effects of Bisacodyl on Ascending Colon Emptying and Overall Colonic Transit in Healthy Volunteers. Alimentary Pharmacology \& Therapeutics, 30, 930-936. https://doi.org/10.1111/j.1365-2036.2009.04118.x

[22] Tack, J., Camilleri, M., Dubois, D., Vandeplassche, L., Joseph, A. and Kerstens, R. (2015) Association between Health-Related Quality of Life and Symptoms in Patients with Chronic Constipation: An Integrated Analysis of Three Phase 3 Trials of Prucalopride. Neurogastroenterology \& Motility, 27, 397-405. https://doi.org/10.1111/nmo.12505

[23] Holzer, P., Ahmedzai, S.H., Niederle, N., Leyendecker, P., Hopp, M., Bosse, B., Spohr, I. and Reimer, K. (2009) Opioid-Induced Bowel Dysfunction in Cancer-Related Pain: Causes, Consequences, and a Novel Approach for Its Management. Journal of Opioid Management, 5, 145-151.

[24] Mehendale, S.R. and Yuan, C.S. (2006) Opioid-Induced Gastrointestinal Dysfunction. Digestive Diseases, 24, 105-112. https://doi.org/10.1159/000090314

[25] Bell, T., Annunziata, K. and Leslie, J.B. (2009) Opioid-Induced Constipation Negatively Impacts Pain Management, Productivity, and Health-Related Quality of Life: Findings from the National Health and Wellness Survey. Journal of Opioid Management, 5, 137-144.

[26] Gupta, S., Patel, H., Scopel, J. and Mody, R.R. (2015) Impact of Constipation on Opioid Therapy Management among Long-Term Opioid Users, Based on a Patient Survey. Journal of Opioid Management, 11, 325-338. https://doi.org/10.5055/jom.2015.0282

[27] Müller-Lissner, S., Bassotti, G., Coffin, B., Drewes, A.M., Breivik, H., Eisenberg, E., Emmanuel, A., Laroche, F., Meissner, W. and Morlion, B. (2016) Opioid-Induced Constipation and Bowel Dysfunction: A Clinical Guideline. Pain Medicine, Online.

Submit or recommend next manuscript to SCIRP and we will provide best service for you:

Accepting pre-submission inquiries through Email, Facebook, LinkedIn, Twitter, etc. A wide selection of journals (inclusive of 9 subjects, more than 200 journals)

Providing 24-hour high-quality service

User-friendly online submission system

Fair and swift peer-review system

Efficient typesetting and proofreading procedure

Display of the result of downloads and visits, as well as the number of cited articles

Maximum dissemination of your research work

Submit your manuscript at: http://papersubmission.scirp.org/

Or contact ojgas@scirp.org 